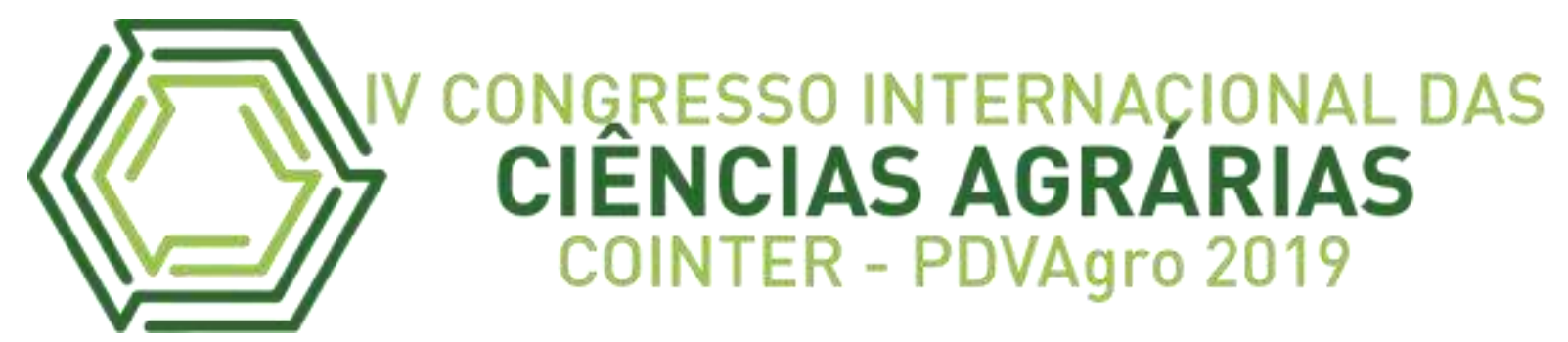

\title{
PERCEPÇÃO DE ACADÊMICOS DE CIÊNCIAS BIOLÓGICAS E ENGENHARIA AGRONÔMICA DO IFPI URUÇUÍ SOBRE OS IMPACTOS AMBIENTAIS RELACIONADOS AO AGRONEGÓCIO
}

\section{PERCEPCIÓN DE LAS ACADÉMICAS DE LAS CIENCIAS BIOLÓGICAS Y LA INGENIERÍA AGRONÓMICA DE LA IFPI URUÇUÍ SOBRE LOS IMPACTOS AMBIENTALES RELACIONADOS CON LA AGRICULTURA}

\section{PERCEPTION OF ACADEMICS OF BIOLOGICAL SCIENCES AND AGRONOMIC ENGINEERING OF IFPI URUÇUÍ ON AGRIBUSINESS-RELATED ENVIRONMENTAL IMPACTS}

\author{
Apresentação: Comunicação Oral \\ Tyago Henrique Alves Saraiva Ciprianoㅜㄹ João Henrique Barros Martins ${ }^{2}$; Anelise dos Santos \\ Mendonça ${ }^{3}$ Lorrane Ribeiro de Mesquita ${ }^{4}$; Brunna Laryelle Silva Bomfim ${ }^{5}$
}

DOI: https://doi.org/10.31692/2526-7701.IVCOINTERPDVAgro.2019.0014

\section{Resumo}

O aumento das populações humanas, em especial nos grandes centros urbanos, elevou, concomitantemente, a demanda no que diz respeito à alimentação. Nessa perspectiva, técnicas voltadas para otimização da produção alimentícia foram aprimoradas, surgindo assim o agronegócio, o qual está relacionado com todas as cadeias de operações agropecuárias. Diante do exposto, objetivou-se analisar a percepção de estudantes de Ciências Biológicas e Engenharia Agronômica do Instituto Federal do Piauí, campus Uruçuí, em relação aos impactos do agronegócio no meio ambiente. Para o desenvolvimento dos aspectos metodológicos, foram aplicados questionários constituído por questões abertas e fechadas à discentes do VI período do curso de Ciências Biológicas e Engenharia Agronômica do Campus Uruçuí do Instituto Federal do Piauí. Antes de responderem ao questionário, os alunos assinaram o Termo de Consentimento Livre e Esclarecido (TCLE). A partir das respostas dos 35 alunos das duas áreas

\footnotetext{
${ }^{1}$ Acadêmico do curso de Licenciatura em Ciências Biológicas, Instituto Federal do Piauí - Campus Uruçuí, e-mail: tyagohenrique98@gmail.com

${ }^{2}$ Acadêmico do curso de Licenciatura em Ciências Biológicas, Instituto Federal do Piauí - Campus Uruçuí, e-mail: j.henriquebm.7@gmail.com

${ }^{3}$ Professora Doutora em Genética e Bioquímica, Instituto Federal do Triângulo Mineiro, IFTM, e-mail: anelise.mendonca@yahoo.com.br

4 Professora Mestre em Ciência Animal, Instituto Federal do Piauí - Campus Angical, e-mail: lorrane.mesquita@ifpi.edu.br

${ }^{5}$ Professora Mestre em Desenvolvimento e Meio Ambiente, Instituto Federal do Piauí - Campus Uruçuí, e-mail: brunnalaryelle@yahoo.com.br
} 
analisadas, foi possível observar que os mesmos apresentam conceitos formados do que é e qual a finalidade do agronegócio. Quanto aos benefícios que o agronegócio proporcionou ao município de Uruçuí-PI, para os entrevistados, houve um significativo desenvolvimento econômico. Contudo, dados do IBGE mostram que municípios que apresentam predominantimente a prática do agronegócio revelam estruturas sociais excludentes, uma vez que esses municipios apresentam PIBs consideralvelmente elevados em relação ao Índice de Desenvolvimento Humano, como foi observado em Uruçuí-PI. Quando o quesito analisado foi a economia, alimentação e geração de empregos em um país, ambos os grupos analisados, Biólogos e Agrônomos, acreditam que a prática do agronegócio pode influenciar positivamente o desenvolvimento local. Entretanto, uma parcela considerável dos acadêmicos de Licenciatura em Ciências Biológicas acredita que o aumento da demanda de produção influencia negativamente o meio ambiente e, em especial, à saúde pública. Em detrimento à concepção dos licenciando, os alunos do curso de agronomia afirmaram que estes impactos somente são gerados quando há uma má utilização dos mecanismos de produção, a exemplo dos agroquímicos. Por isso, é imprescindível que o uso dos agrotóxicos se dê de forma consciente, já que o seu manejo inadequado pode afetar aqueles que são expostos de forma direta e indireta. Nesse sentido, resta claro a necessidade de preservação dos ecossistemas e, para isso, técnicas sustentáveis são alternativas viáveis que as empresas relacionadas ao ramo do agronegócio podem aplicar às suas práticas produtivas. Isso porque quando esses setores trabalham com questões relacionadas à sustentabilidade, impactos que outrora eram gerados ao ambiente, são minimizados.

Palavras-Chave: Agropecuária; Degradação; Saúde; Sustentabilidade.

\section{Resumen}

El aumento de las poblaciones humanas, especialmente en los grandes centros urbanos, ha aumentado simultáneamente la demanda de alimentos. Desde esta perspectiva, se han mejorado las técnicas destinadas a optimizar la producción de alimentos, lo que resulta en agronegocios, lo que está relacionado con todas las cadenas de operaciones agrícolas. Dado lo anterior, el objetivo fue analizar la percepción de los estudiantes de Ciencias Biológicas e Ingeniería Agrícola del Instituto Federal de Piauí, campus de Uruçuí, en relación con los impactos de los agronegocios en el medio ambiente. Para el desarrollo de los aspectos metodológicos, se aplicaron cuestionarios compuestos por preguntas abiertas y cerradas a estudiantes del VI período del curso de Ciencias Biológicas e Ingeniería Agronómica del Campus Uruçuí del Instituto Federal de Piauí. Antes de responder el cuestionario, los estudiantes firmaron el Formulario de Consentimiento Informado (ICF). A partir de las respuestas de los 35 estudiantes de las dos áreas analizadas, fue posible observar que se han formado conceptos de qué es y cuál es el propósito del agronegocio. En cuanto a los beneficios que los agronegocios proporcionaron al municipio de Uruçuí-PI, para los entrevistados, hubo un desarrollo económico significativo. Sin embargo, los datos del IBGE muestran que los municipios que tienen predominantemente prácticas de agronegocios muestran estructuras sociales excluyentes, ya que estos municipios tienen un PIB considerablemente más alto en relación con el Índice de Desarrollo Humano, como se observa en Uruçuí-PI. Cuando la pregunta analizada fue la economía, la alimentación y la creación de empleo en un país, ambos grupos analizados, biólogos y agrónomos, creen que la práctica de los agronegocios puede influir positivamente en el desarrollo local. Sin embargo, una parte considerable de los estudiantes de pregrado en Ciencias Biológicas creen que el 
aumento en la demanda de producción influye negativamente en el medio ambiente y, en particular, en la salud pública. En detrimento de la concepción de los estudiantes universitarios, los estudiantes del curso de agronomía declararon que estos impactos solo se generan cuando hay un mal uso de los mecanismos de producción, como los agroquímicos. Por lo tanto, es esencial que el uso de pesticidas ocurra conscientemente, ya que su manejo inadecuado puede afectar a aquellos que están expuestos directa e indirectamente. En este sentido, es evidente la necesidad de preservar el ecosistema y, para ello, las técnicas sostenibles son alternativas viables que las empresas de agronegocios pueden aplicar a sus prácticas de producción. Esto se debe a que cuando estos sectores trabajan en temas de sostenibilidad, los impactos que una vez se generaron en el medio ambiente se minimizan.

Palabras Clave: Agricultura, Degradación, Salud, Sustentabilidad.

\begin{abstract}
The increase in human populations, especially in large urban centers, has simultaneously increased demand for food. From this perspective, techniques aimed at optimizing food production have been improved, resulting in agribusiness, which is related to all agricultural operations chains. Given the above, the objective was to analyze the perception of students of Biological Sciences and Agricultural Engineering of the Federal Institute of Piauí, Uruçuí campus, in relation to the impacts of agribusiness on the environment. For the development of the methodological aspects, questionnaires consisting of open and closed questions were applied to students of the VI period of the Biological Sciences and Agronomic Engineering course of the Uruçuí Campus of the Federal Institute of Piauí. Before answering the questionnaire, the students signed the Informed Consent Form (ICF). From the responses of the 35 students from the two areas analyzed, it was possible to observe that they have formed concepts of what is and what is the purpose of agribusiness. Regarding the benefits that agribusiness provided to the municipality of Uruçuí-PI, for the interviewees, there was a significant economic development. However, data from the IBGE show that municipalities that predominantly have agribusiness practices show exclusionary social structures, since these municipalities have considerably higher GDPs relative to the Human Development Index, as observed in Uruçuí-PI. When the question analyzed was the economy, food and job creation in a country, both analyzed groups, Biologists and Agronomists, believe that the practice of agribusiness can positively influence local development. However, a considerable portion of undergraduate students in Biological Sciences believe that the increase in production demand negatively influences the environment and, in particular, public health. To the detriment of the undergraduates' conception, students of the agronomy course stated that these impacts are only generated when there is a misuse of production mechanisms, such as agrochemicals. Therefore, it is essential that the use of pesticides occurs consciously, as their improper handling can affect those that are exposed directly and indirectly. In this sense, it is clear the need for ecosystem preservation and, for this, sustainable techniques are viable alternatives that agribusiness companies can apply to their production practices. This is because when these sectors work on sustainability issues, impacts that were once generated on the environment are minimized.
\end{abstract}

Keywords: Farming, Degradation, health, Sustainability. 


\section{Introdução}

O setor agropecuário vem se destacando em seus meios de produção com os elevados ganhos de produtividade e/ou rentabilidade para o território Nacional. Este aspecto está relacionado aos avanços tecnológicos do setor produtivo, o qual o direciona para uma alta representatividade da economia do país, já que o Brasil dispõe de 388 milhões de hectares agricultáveis (GILIO et al., 2016; STEFFEN NETO, 2015).

Seguindo essa perspectiva, estima-se que a área cultivada do Brasil se elevou a aproximadamente 53\% nas quatro últimas décadas, ou seja, aproximadamente 330 milhões de hectares são ocupados por propriedades rurais, sendo produzidas por elas, em média, $3.484 \mathrm{~kg}$ de alimento por hectare (SILVEIRA et al., 2018).

No entanto, é necessário entender quais riscos podem estar associados ao crescimento do agronegócio para o meio ambiente, tendo em vista que a má utilização de mecanismos destinados à otimização de práticas agropecuárias pode refletir de forma negativa para o homem e/ou para a natureza. Assim, o Brasil é destaque no que diz respeito a utilização de agrotóxicos nas produções, entretanto, a sua utilização pode acarretar interferências diretas no ambiente (SOUZA; SOUZA JÚNIOR; VIEIRA, 2017).

Infelizmente, a expansão do agronegócio no Brasil não está associada à sustentabilidade dos recursos naturais, uma vez que suas atividades têm provocado a degradação e contaminação do solo, comprometendo a qualidade das águas dos sistemas hídricos, incluindo mananciais, nascentes e as águas subterrâneas (GOMES, 2019).

Práticas de produções sustentáveis estão relacionadas à melhoria da produção, podendo ela contribuir para o desenvolvimento econômico sem agredir de forma significativa o ambiente (VALLE NETO, 2014). Uma alternativa economicamente viável seria o investimento em técnicas sustentáveis como a rotação de cultura e/ou plantio direto, dentre outras que visem minimizar a degradação do ambiente (SILVA, 2018).

Nesse sentido, justificou-se o desenvolvimento deste estudo, uma vez que por mais que pesquisas sobre os impactos ambientais oriundos de práticas relacionadas ao agronegócio tenham se elevado bastante nos últimos anos, ainda são insuficientes diante da imensa carga química de exposição e danos à saúde pública decorrentes da utilização de agrotóxicos (ARAÚJO; OLIVEIRA, 2017). 
Dessa forma, o presente trabalho buscou levantar informações sobre a percepção de estudantes de Ciências Biológicas e Engenharia Agronômica do Instituto Federal do Piauí, campus Uruçuí, em relação aos impactos do agronegócio no meio ambiente.

\section{Fundamentação Teórica}

Os primeiros registros de áreas agrícolas foram observados há milhares de anos, os quais se aperfeiçoaram com os avanços tecnológicos sofridos pelas populações humanas, a exemplo do processo de irrigação e, consequentemente, melhor aproveitamento das áreas de plantio; assim, o aprimoramento de técnicas agrícolas subsidiou o desenvolvimento de atividades comerciais por essas comunidades, especialmente no que diz respeito à troca de produtos (BURANELLO, 2018).

Desde então, a agricultura percorreu por várias etapas até chegar ao patamar que se observa no cenário atual. Nesse sentido, merece destaque a agricultura tropical, em especial a agricultura brasileira na região do Cerrado (GOMES et al., 2016). Segundo os autores, o país elevou significativamente a produção nos últimos 40 anos, alcançando os grandes exportadores de grãos: Estados Unidos, Canadá, Austrália, Argentina e União Europeia.

Em 1960, políticas públicas para o desenvolvimento do agronegócio começaram a ser implementadas, como a criação do Sistema Nacional de Crédito Rural (SNCR) em 1964, do Crédito Rural em 1965, da Empresa Brasileira de Pesquisas Agropecuárias (EMBRAPA) em 1973 para desenvolver pesquisas agropecuárias, visando um aumento na produtividade sem agredir de forma significativa o ambiente e, posteriormente, em 1996, a criação do Programa Nacional de Fortalecimento da Agricultura Familiar - Pronaf (SOUSA; OLIVEIRA, 2018).

A definição para o termo agronegócio foi proposta por Davis e Goldberg (1957), os quais o definem como a relação que envolve toda a cadeia de operações. Coelho $(2013$, p. 16) esclarece tal conceito:

O agronegócio não se limita, assim, especificamente à plantação e cultivo das commodities agrícolas (cana, soja, milho, trigo, café etc.), embora esta atividade esteja no centro da rede agronegocial. Também a integram a produção e comercialização de sementes, adubos e demais insumos, distribuição, armazenamento, logística, transporte, financiamento, conferência de qualidade e outros serviços, bem como o aproveitamento de resíduos de valor econômico. É, na verdade, a interligação racional de todas essas atividades econômicas que compõem o agronegócio, e não cada uma delas em separado.

Sousa e Oliveira (2018) acreditam que a legislação brasileira, no que diz respeito aos 
dispositivos que asseguram o meio ambiente, atualmente, é considerada uma das mais completas do mundo, apesar disso, há uma falta de fiscalização pelo poder público e/ou comprometimento pelos produtores, visto que ainda é possível encontrar falhas neste seguimento legal.

A Organização das Nações Unidas (ONU) afirmou que a população global atual é de 7,6 bilhões de habitantes, a qual dará um salto de 1 bilhão de pessoas até o ano de 2030 (ONU, 2017). Dessa forma, o aumento da população ocasionará, concomitantemente, um salto na produção agrícola mundial. A agricultura em larga escola, caracterizada em especial pelo uso intensivo de tecnologias e agrotóxicos, tem possibilitado uma produção alimentícia que até então atende as demandas populacionais, contudo, impactos negativos são gerados ao ambiente devido à sua utilização (OLIVEIRA; CAMARGO, 2014).

O agronegócio é um fator essencial para o setor econômico do país e do mundo, entretanto, é importante que os países que dispõem desta prática aliem suas ideias aos mecanismos voltados para preservação do meio ambiente, com ênfase nos critérios de sustentabilidade, de modo que o desenvolvimento se dê em todas as suas esferas: econômica, social, política, cultural e, também, individual (COSTA; LINO, 2018).

\section{Metodologia}

\section{Área de estudo}

O município de Uruçuí $\left(07^{\circ} 13^{\prime} 46^{\prime \prime}\right.$ S e 443’22’'W) localiza-se na microrregião do Alto Parnaíba Piauiense, distante 453 Km da capital do estado do Piauí (AGUIAR; BARROS, 2004). Com população de 20.149 habitantes, o município possui clima tropical subúmido quente, e temperaturas médias entre $20^{\circ} \mathrm{C}$ a $31^{\circ} \mathrm{C}$, e como vegetação típica o Cerrado (CEPRO, 2010; IBGE, 2010).

O campus do Instituto Federal do Piauí (IFPI) situado na cidade de Uruçuí oferta cursos de ensino médio integrado ao técnico em Administração, Agroindústria e Agropecuária, curso técnico subsequente em Agronegócio, além dos cursos superiores de Licenciatura Plena em Matemática, Licenciatura Plena em Ciências Biológicas e Bacharelado em Engenharia Agronômica. Possuindo atualmente mais de 850 alunos, sendo 140 graduandos de Biologia e 150 graduandos de Engenharia Agronômica. 
Foi adotada a metodologia de pesquisa do tipo descritivo com abordagens de forma qualitativa e quantitativa.

O levantamento de dados foi feito mediante aplicação de questionário, constituído com questões abertas e fechadas à discentes do curso de Ciências Biológicas e Engenharia Agronômica do Campus Uruçuí do Instituto Federal do Piauí, com os discentes do VI período das duas áreas. A escolha dos alunos destas turmas se deu por terem cursado mais de $50 \%$ do curso e tendo desenvolvido senso crítico sobre assuntos ligados a impactos ao meio ambiente.

No momento da coleta de dados, foi solicitado do professor presente na sala de aula, permissão para aplicação do questionário. Foi repassado pelo pesquisador para cada um dos alunos, as informações sobre a pesquisa, sendo respeitada a decisão em se abster da participação. Foram entrevistados todos os alunos presentes na sala de aula e que aceitaram, voluntariamente, participar da pesquisa. Antes de responderem ao questionário, os alunos assinaram o Termo de Consentimento Livre e Esclarecido (TCLE).

Ao final da pesquisa, foi realizada palestra sobre os impactos positivos e negativos do agronegócio, bem como sobre as atividades sustentáveis no setor.

\section{Resultados e Discussão}

Foram entrevistados 35 alunos, sendo 18 acadêmicos do curso de Licenciatura em Ciências Biológicas e 17 de Engenharia Agronômica, os quais apresentaram idades entre 19 e 38 anos. Quando questionados sobre a definição do termo agronegócio, os participantes da pesquisa, afirmaram que o mesmo está ligado à economia e à agricultura de um país, sendo inerente a este um interesse comercial e/ou industrial. Tais características podem ser observadas na fala de um dos entrevistados ao definir o agronegócio como "toda a relação comercial $e$ industrial envolvendo a cadeia agrícola e pecuária de um país" (Sr. A. 21).

Não se encontra, na literatura atual, uma definição clara e objetiva do que é o agronegócio. Essa dificuldade também foi encontrada por Cazetta (2018), ao realizar uma revisão de literatura em busca dessa definição. Para a autora, ela aparece de forma implícita, sem explicitar diretamente do que se trata e/ou significa. Dessa forma, a definição encontrada e mais aceita é a de Davis e Goldberg (1957), que diz que o agronegócio pode ser compreendido como a relação que envolve toda a cadeia de operações, desde a fabricação dos insumos, a produção, a industrialização, a distribuição e a comercialização do produto obtido ao final deste ciclo produtivo. 
Com o aumento da população e a insuficiência no que diz respeito à alimentação, é que se justifica a elevada produção agrícola no país, no entanto, apesar disso, é importante salientar que o aumento da produtividade agrícola e, concomitantemente, a expansão do agronegócio, impactos socioambientais e à saúde pública podem ser gerados, tendo em vista a concentração de terras, a migração campo-cidade e, principalmente, a utilização de agroquímicos para otimizar essa produção e minimizar os riscos de perdas para pragas (ARAÚJO; OLIVEIRA, 2017).

Nesse contexto, os entrevistados foram questionados sobre a importância do agronegócio para o país. Todos os participantes afirmaram que o agronegócio é uma alternativa para otimizar a produção e atender as necessidades populacionais, especialmente no que tange à economia, à geração de empregos e à alimentação, sendo esta última má distribuída no território nacional. No entanto, uma parcela considerável dos entrevistados não acredita que este seria importante para a saúde, de forma que muitos afirmaram que não só não ajuda como prejudica esse setor público (Figura 1).

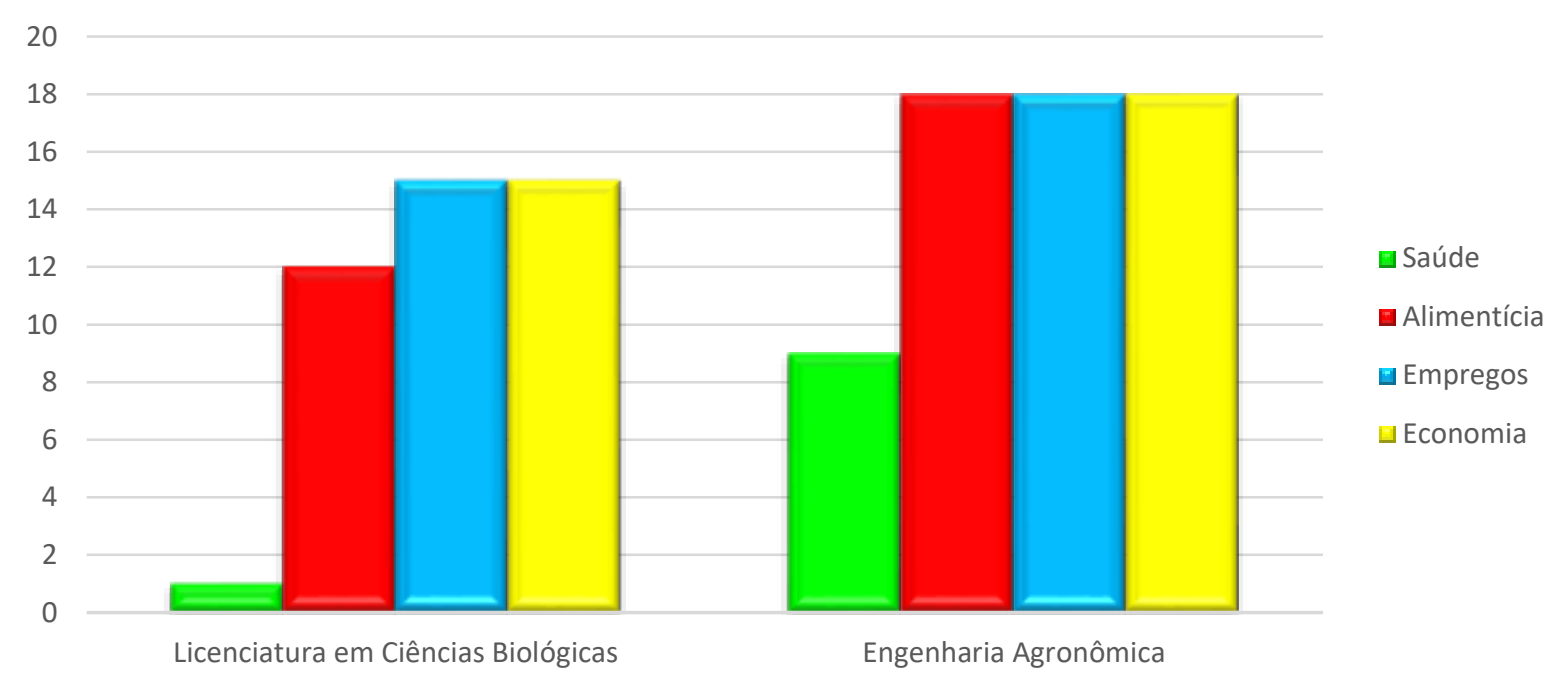

Figura 1: Concepção dos acadêmicos dos cursos de Licenciatura em Ciências Biológicas e Engenharia Agronômica acerca da importância do agronegócio, associada aos diferentes segmentos.

Fonte: Própria (2019).

É possível observar na figura 1 as semelhanças e controvérsias existentes entre as respostas dos diferentes grupos de entrevistados, os quais apresentam visões relativamente semelhantes no que diz respeito aos benefícios que podem ser associados ao agronegócio quando o quesito é a economia, alimentação e geração de empregos em um país, no caso o 
Brasil. Entretanto, quando o assunto é saúde, uma parcela considerável destes, especialmente os do curso de Licenciatura em Ciências Biológicas (94\%), acreditam que o agronegócio pode acarretar problemas à saúde da população, já os alunos do curso de Engenharia Agronômica dividem opiniões quando questionados sobre os prejuízos causados pelo agronegócio à saúde das pessoas: 54\% não associam a prática do agronegócio a problemas à saúde e $46 \%$ dos entrevistados entendem que a estrutura necessária à prática do agronegócio traz riscos inerentes à saúde das pessoas.

A concepção dos participantes sobre os prejuízos do agronegócio que podem refletir na saúde das pessoas está relacionada ao uso excessivo de agrotóxicos, uma vez que Araújo e Oliveira (2017) afirmaram em seus estudos que o uso excessivo e inadequado de agrotóxicos pode afetar a saúde dos consumidores de alimentos contaminados, famílias que moram no entorno dessas áreas de produção, bem como os trabalhadores que são expostos a esses produtos.

Ao estudarem os impactos dos agrotóxicos à saúde, ao trabalho e ao ambiente no contexto do agronegócio no Brasil, Carneiro et al. (2014) constataram, ao examinar os Auxílios Doenças e Auxílios Acidentes concedidos pelo Instituto Nacional do Seguro Social (INSS), que dentre as causas de acidentes que ocorreram entre 1999 e 2005, o maior percentual foi daqueles advindos de lesões por envenenamento e consequências de causas externas, com 78,1\% em 1999 e 78,3\% em 2005.

Em relação aos impactos gerados ao ambiente pela ação do agronegócio, ambos os grupos de entrevistados, acadêmicos de Biologia e Agronomia, afirmaram que o agronegócio gera algum tipo de impacto ao ambiente (83\% e $82 \%$, respectivamente) (Tabela 1). Para o primeiro grupo, estes problemas estão associados à contaminação de solos e/ou rios, poluição, aumento no aquecimento global, degradação do solo, dentre outras formas. O segundo grupo, por outro lado, acredita que o impacto está associado, especialmente, ao desmatamento em larga escala, sendo a contaminação de rios e/ou solos causados unicamente pelo uso inadequado desses mecanismos.

Tabela 1: Concepção dos acadêmicos dos cursos de Licenciatura em Ciências Biológicas e Engenharia Agronômica acerca dos efeitos do agronegócio no país.

\begin{tabular}{ccc|c}
\hline \multirow{2}{*}{ Parâmetros } & \multicolumn{2}{|c|}{ Biologia } & \multicolumn{2}{|c}{ Agronomia } \\
\cline { 2 - 3 } & Sim Não & Sim Não \\
\hline
\end{tabular}




\begin{tabular}{lll|ll}
\hline O agronegócio gera impacto ambiental & $83 \%$ & $17 \%$ & $82 \%$ & $18 \%$ \\
\hline O agronegócio gera impacto para o homem & $94 \%$ & $6 \%$ & $29 \%$ & $71 \%$ \\
\hline O agronegócio proporciona benefícios para a natureza & $11 \%$ & $89 \%$ & $59 \%$ & $41 \%$ \\
\hline O agronegócio proporciona benefícios para o homem & $100 \%$ & - & $100 \%$ & - \\
\hline
\end{tabular}

Fonte: Própria (2019).

Em estudos acerca de externalidades negativas causadas ao meio ambiente pela expansão do agronegócio no Brasil, Sousa e Oliveira (2018) listaram algumas práticas associadas ao agronegócio que geram impactos à natureza, quais sejam: o uso inapropriado de defensivos agrícolas; o aumento excessivo das áreas de plantio; técnicas não recomendáveis para produção, a exemplo das queimadas de pastagens ou nas plantações de cana-de-açúcar; o descarte incorreto de embalagens de agrotóxicos; o descarte de rejeitos em ambientes como rios e/ou lagos por parte das indústrias do agronegócio e o desmatamento descontrolado para ampliação das áreas de plantio.

Em relação aos entrevistados que acreditam que a expansão do agronegócio não afeta negativamente o meio ambiente, é possível observar, ainda na tabela 1, um percentual de $17 \%$ para o curso de Licenciatura em Ciências Biológicas e 18\% para Engenharia Agronômica. Paiva e Santos (2018) dizem que a falta de informação dos produtores e da população em geral é um problema cotidianamente enfrentado pelo poder público, já que muitas vezes esses indivíduos não sabem dos riscos a que estão submetidos.

Em se tratando dos impactos gerados aos seres humanos, $94 \%$ dos acadêmicos do curso de Licenciatura em Ciências Biológias acreditam que os impactos que afetam a natureza também podem afetar o homem. Já que "por estar diretamente ligado à natureza, o homem sofre junto a ela por fazer parte do mesmo contexto ecológico" (Sr. B. 20). No que se refere ao contexto urbano-ambiental, áreas verdes são importantes por inúmeros fatores, dentre eles estão a regulação do clima urbano, bem estar socioemocional da população, assim como o controle térmico dos indivíduos que ali estão presentes (BARROS et al., 2017). Dessa forma, o desmatamento, as queimadas e o manejo inadequado do solo podem refletir negativamente nesses aspectos. 
Em contrapartida, 71\% dos alunos do curso de Engenharia Agronômica acreditam que o agronegócio não afeta negativamente o homem, e sim positivamente, desde que seja praticado de forma apropriada pelos produtores, em conformidade com os dispositivos legais que o regulamentam. Tal informação também é evidenciada nos estudos de Buffolo e Rodrigues (2015) ao analisarem a temática "agrotóxicos", na articulação de conhecimentos químicos e questões socioambientais com alunos do ensino médio, evidenciando, em uma das categorias analisadas, os benefícios da utilização dos agrotóxicos, os quais são de fundamental importância para otimizar a produção e atender às necessidades populacionais no que diz respeito à alimentação.

Apesar de concordarem que o agronegócio gera impactos negativos ao meio ambiente e também ao homem, todos os entrevistados concordam que o agronegócio não gera apenas malefícios, mas beneficios para a sociedade, uma vez que aquece a economia, e produz em um nível acelerado, possibilitando o abastecimento das necessidades de alimentação da população.

No que tange à sustentabilidade, Silveira et al. (2018) acreditam que a preservação do meio ambiente, bem como organizações sustentáveis econômicas e o manejo adequado desses recursos seja uma alternativa para minimizar os impactos negativos e otimizar os positivos, tanto para o homem como para a natureza. O que corrobora com as informações obtidas através de questionamentos feitos aos acadêmicos de Licenciatura em Ciência Biológicas, já que 89\% dos participantes afirmaram que o uso consciente desses recursos seria uma alternativa para diminuir os impactos negativos e gerar benefícios à natureza.

Em detrimento a isto, uma parcela significativa dos alunos do curso superior em Engenharia Agronômica (54\%) acreditam que o agronegócio não gera impactos à natureza, e $46 \%$ dos mesmos que discordam desta afirmação. A prática do agronegócio vem crescendo de forma elevada no país, a qual se estende a um terço de toda a superfície terrestre, porém, no Brasil, mais de $62 \%$ da área total é preservada, destacando-se como uma das mais avançadas do mundo em termos de legislação (BURANELLO, 2013), o que evidencia que há, no contexto nacional, parâmetros que asseguram a preservação da natureza.

Costa (2018) acredita que, apeser da vasta legislação nacional voltada para os cuidados com o meio ambiente, os impactos da agricultura são notoriamente observados, visto que ainda é possível se encontrar, entre os meios de produção, o uso inapropriado de irrigação, agrotóxicos, assim com dos maquinários utilizados nessas lavouras. É nessa perspectiva que 
surge a importância da Nacional de Meio Ambiente, instituída pela Lei 6.938/81, a qual prevê a Avaliação de Impacto Ambiental.

Quando questionados sobre o que poderia ser desenvolvido para otimizar a produção e minimizar os impactos gerados ao homem e, sobretudo, ao meio ambiente, os participantes afirmaram que técnicas voltadas para a sustentabilidade seria uma alternativa. "Tentar alcançar a sustentabilidade, respeitando o meio ambiente e as políticas sociais é uma atividade economicamente viável" (Sr. C. 20).

É importante que empresas do ramo do agronegócio associem-se e visem a sustentabilidade do planeta, garantido as presentes e futuras gerações, a qualidade de vida no ambiente, assim como incorporar aos seus discursos atividades de educação ambiental; uma vez que o consumidor também pode se sensibilisar sobre esse viés sustentável (VELHO; MACHADO, 2018).

Na tabela 2 é possível observar o avanço consideraveel do IDH do município de UruçuíPI com a presença do agronegócio, o qual deu um salto de 0,432 no ano de 2000 para 0,631 no ano de 2010 , subindo para $16^{\circ}$ posição em relação aos demais municipios do estado. No entanto, municípios que apresentam predominantimente a prática do agronegócio revelam estruturas sociais excludentes, uma vez que a relação PIB per capita e IDH evidenciam tal informação. É possível observar essa situação em municípios que apresentam PIBs consideralvelmente elevados em relação ao Índice de Desenvolvimento Humano, como é o caso de Uruçuí-PI, que possui o $2^{\circ}$ maior PIB per capita do estado, no entanto, o IDH ocupa a $16^{\circ}$ posição (CEPRO, 2010; IBGE, 2010).

Tabela 2. Evolução do Índice de Desenvolvimento Humano (IDH) em municípios do Piauí.

\begin{tabular}{lccccc}
\hline \multicolumn{1}{c}{ Municípios* } & 1991 & 2000 & 2010 & $\begin{array}{c}\text { Crescimento } \\
2000-2010\end{array}$ & $\begin{array}{c}\text { Posição do } \\
\text { Estdo }\end{array}$ \\
\hline Brasil & 0,493 & 0,612 & 0,727 & 0,115 & - \\
\hline Piauí & 0,362 & 0,484 & 0,646 & 0,162 & - \\
\hline Guadalupe & 0,401 & 0,495 & 0,650 & 0,155 & $8^{\mathrm{a}}$ \\
\hline Uruçuí & 0,294 & 0,432 & 0,631 & 0,199 & $16^{\mathrm{a}}$ \\
\hline Antônio Almeida & 0,320 & 0,478 & 0,620 & 0,142 & $22^{\mathrm{a}}$ \\
\hline Bertolínia & 0,343 & 0,441 & 0,612 & 0,171 & $29^{\mathrm{a}}$ \\
\hline Ribeiro Gonçalves & 0,333 & 0,439 & 0,601 & 0,162 & $35^{\mathrm{a}}$ \\
\hline Jerumenha & 0,368 & 0,448 & 0,591 & 0,143 & $44^{\mathrm{a}}$ \\
\hline Marcos Parente & 0,364 & 0,466 & 0,590 & 0,124 & $45^{\mathrm{a}}$ \\
\hline Landri Sales & 0,367 & 0,451 & 0,584 & 0,133 & $51^{\mathrm{a}}$ \\
\hline Canavieira & 0,267 & 0,388 & 0,583 & 0,195 & $52^{\mathrm{a}}$ \\
\hline Baixa Grande do Ribeiro & 0,202 & 0,349 & 0,564 & 0,215 & $69^{\mathrm{a}}$ \\
\hline Porto Alegre do Piauí & 0,264 & 0,374 & 0,563 & 0,189 & $70^{\mathrm{a}}$ \\
\hline Sebastião Leal & 0,219 & 0,369 & 0,562 & 0,193 & $71^{\mathrm{a}}$ \\
\hline
\end{tabular}


Fonte: Fundação CEPRO. *Os municípios estão ordenados conforme o IDHM de 2010, do maior para o menor.

Para a maioria dos entrevistados, o agronegócio proporcionou inúmeros benefícios para o município de Uruçuí-PI. Dentre os benefícios mencionados pelos participantes da pesquisa destaca-se o crescimento das oportunidades de emprego, sejam de forma direta ou indireta. No entanto, alguns participantes destacaram impactos ocasionados pela presença do agronegócio na região, o que pode ser percebido na fala de um deles ao dizer que:

\footnotetext{
"Acredito que tenham sido mais benefícios do que malefícios, porém, pode-se dizer que a grande quantidade de agrotóxicos utilizados resulta em contaminação, além de certos desequilíbrios ecológicos que podem ter sido ocasionados pela presença de monoculturas. Contudo, precisamos de alimento e no presente cenário do mundo há riscos a se correr para isso" (Sr. D. 21).
}

Em relação as respostas dos dois grupos analisados, é possível observar que algumas informações se assemelham, especialmente no que se refere à finalidade do agronegócio para o País. Contudo, quando o assundo estende-se para os impactos que são gerados pelas práticas do agronegócio, tanto na natureza como para o homem, as respostas destes diferentens nichos acabam divergindo, visto que para os licenciandos os impactos negativos sempre serão gerados, especialmente pela exposiçao de agrotóxicos ao qual as pessoas e/ou o ambiente são submetidos. Em contraparte, o outro grupo (agrônomos) acredita que estes impactos somente ocorrem quando há uma má utilização destes mecanismos.

\section{Conclusões}

Com o aumento das demandas econômicas e sociais, bem como a necessidade de atender a população, houve um salto significativo no que diz respeito ao agronegócio no país, o qual compreende todo o processo de produção, desde a fabricação dos insumos até a comercialização do produto que é obtido ao final deste ciclo.

Apesar de inúmeros benefícios serem associados ao agronegócio no que tange à economia, à geração de empregos e à alimentação, o aumento do ciclo produtivo pode gerar problemas tanto para o ambiente como para o homem, tendo em vista que o manejo inadequado dos recursos naturais que são utilizados para fins agropecuários degrada o ambiente e geram consequências à saúde pública.

É importante ressaltar que quando empresas do ramo da agropecuária trabalham com 
questões relacionadas à sustentabilidade, impactos que outrora eram gerados ao ambiente são minimizados. Assim, resta claro que um olhar diferenciado para o meio ambiente é uma alternativa economicamente viável.

Tendo em vista a importância de se conservar o meio ambiente, otimizando as atividades e reduzindo os impactos gerados neste meio, espera-se que este estudo sirva de instrumento para sensibilização acerca dessas questões. Fazem-se ainda necessários mais estudos em se tratando da inovação dos modelos sustentáveis utilizados pelas empresas do ramo do agronegócio para sustentabilidade do Meio Ambiente.

\section{Referências}

AGUIAR, R. B.; GOMES, J. R. C. (Orgs). Ministério de Minas e Energia. Projeto cadastro de fontes de abastecimento por água subterrânea, estado do Piauí: diagnóstico do município de Uruçuí. Fortaleza: CPRM - Serviço Geológico do Brasil. 2004.

ARAÚJO, I. M. M.; OLIVEIRA, Â. G. R. DA C. Agronegócio e agrotóxicos: impactos à saúde dos trabalhadores agrícolas no nordeste brasileiro. Saúde, Rio de Janeiro, v. 15 n. 1, p. 117 $129,2017$.

BARROS, A. P. S.; AZEVEDO, A. C. J.; DIAS, E. R. S.; OLIVEIRA, H. M. P. Planejamento urbano, áreas verdes e qualidade de vida: uma análise comparativa entre os bairros Terra Firme e Cidade Velha - Belém/PA. Revista Eletrônica Geoaraguaia, Barra do Garças-MT. V. 7, n. 2, $\quad$ p. $68 \quad-\quad$ 85, 2017. $\quad 68$ Disponível em: < http://periodicoscientificos.ufmt.br/ojs/index.php/geo/article/view/6971/4574> Acesso em 22 Abr. 2019.

BUFFOLO, A. C. C.; RODRIGUES, M. A. Agrotóxicos: uma proposta socioambiental reflexiva no ensino de química sob a perspectiva CTS. Investigações em Ensino de Ciências, V. 20, n. $1, \quad$ p. 1-14, 2015. Disponível em: < https://www.if.ufrgs.br/cref/ojs/index.php/ienci/article/view/56/33> Acesso em 03 Jun. 2019.

BRASIL. Lei 6.938 de 1981. Dispõe sobre a Política Nacional do Meio Ambiente, seus fins e mecanismos de formulação e aplicação, e dá outras providências. Brasília: DOU, 1981.

BURANELLO, R. Manual do direito do agronegócio. Saraiva, São Paulo, 2013.

BURANEllO, R. Manual do Direito do Agronegócio. 2. ed. São Paulo: Saraiva Educação, 2018. Disponível em: < https://books.google.com.br/books?hl=ptBR\&lr=\&id=hdJiDwAAQBAJ\&oi=fnd\&pg=PT5\&dq=surgimento+do+agroneg\%C3\%B3cio \&ots=7iFn8pAuq1\&sig=Ys91Vx6NkPA5T1J7RtaEfLEjaTE\#v=onepage \&q=surgimento\%20d o\%20agroneg\%C3\%B3cio\&f=false > Acesso em 29 Jul. 2019. 
CARNEIRO, F. F.; DELGADO, G.; AUGUSTO, L. G. S.; ALMEIDA, V. S. Os impactos dos agrotóxicos na saúde, trabalho e ambiente no contexto do agronegócio no Brasil. Rio de Janeiro: Abrasco, 2014. Disponível em: < http://www.saudecampofloresta.unb.br/wpcontent/uploads/2014/03/Os-impactos-dos-agrot\%C3\%B3xicos-na-sa\%C3\%BAde-trabalho-eambiente-no-contexto-do-agroneg\%C3\%B3cio-no-Brasil.pdf> Acesso em 10 Fev. 2019.

CAZETTA, A. M. Os interesses e os atores sociais em jogo nos artigos científicos sobre o agronegócio. 2018. 46 f. Trabalho de conclusão de curso (Ciências Sociais). Universidade Federal de Uberlândia, Uberlândia. 2018. Disponível em: < http://repositorio.ufu.br/bitstream/123456789/23677/3/InteressesAtoresSociais.pdf> Acesso em 10 Fev. 2019.

CEPRO. Fundação Centro de Pesquisas Econômicas e Sociais do Piauí. Diagnóstico Sócioeconômico. Município Uruçuí. $2010 . \quad$ Disponível <www.cepro.pi.gov.br/download/201106/CEPRO21_0b5fab9677.pdf> Acesso em $20 \mathrm{Jul}$. 2017.

CEPRO. Fundação Centro de Pesquisas Econômicas e Sociais do Piauí. Piauí em Números. 2010., 8 ed., $\quad$ Teresina $\quad-\quad$ PI. Disponível em: <http://www.cepro.pi.gov.br/download/201105/CEPRO03_01af59957c.Pdf> Acesso em 25 Abr. 2019.

COELHO, F. U. Prefácio. In: Manual do direito do agronegócio. São Paulo: Saraiva, 2013.

COSTA, P. S. P.; LINO, E. N. DA S. O Agronegócio no Brasil: uma análise contra hegemônica voltada à sustentabilidade e ao direito ao desenvolvimento. Revista Videre, Dourados, MS, v.10, n.20, p. 14-28, jul./dez. 2018.

COSTA, P. S. P. O direito e as práticas sustentáveis no agronegócio brasileiro: uma análise pautada na teoria das capacidades humanas. Cadernos de Dereito Actual, n. 10, p. 181-198, 2018.

Disponível em:

http://www.cadernosdedereitoactual.es/ojs/index.php/cadernos/article/view/363/215> Acesso em 03 Jun. 2019.

DAVIS, J. H.; GOLDBERG, R. Concept of agribusiness, Boston: Harvard University, 1957.

GILIO, L.; SILVA, A. F.; BARROS, G. S.A. C.; FACHINELlO, A. L.; CASTRO, N. R. O agronegócio em Minas Gerais: evolução do produto interno bruto entre 2004 e 2015. Revista de Economia e Agronegócio, v.14, n. 1,2, p. 41-76, 2016. Disponível em: < https://periodicos.ufv.br/ojs/rea/article/viewFile/7612/3155> Acesso em 18 Jul. 2019.

GOMES, C. S. Impactos da expansão do agronegócio brasileiro na conservação dos recursos naturais. Cadernos do Leste Artigos Científicos, BeloHorizonte, v. 19, n. 19, 2019.

GOMES, M. P.; GRÜNDLING, R. D. P.; CONTINI, E.; JÚNIOR, P. A. V. Agricultura mundial: evolução, avanços e novos desafios. IN: PICCOLI, G. V.; DALCIN, E.; LOPES, M. A. (Org.). Desafios do cerrado: como sustentar a expansão da produção com produtividade e competitividade. Cuiabá: Editora Casa da Árvore, 2016. Cap. 1. Disponível em: < 
https://www.unifesp.br/reitoria/dci/images/DCI/revistas/Entreteses/guia_referencias_ABNT_ 2014.pdf> Acesso em 29 Jul. 2019.

IBGE. Instituto Brasileiro de Geografia e Estatística. Censo Demográfico - 2010. IN: CEPRO. Fundação Centro de Pesquisas Econômicas e Sociais do Piauí. Informações Municipais Disponível em: 〈http://www.cepro.pi.gov.br/download/201106/CEPRO21_0b5fab9677.pdf> Acesso em 02 Abr. 2019.

OLIVEIRA, A. L. de; CAMARGO, S. G. C. de; Logística reversa de embalagens de agroquímicos: identificação dos determinantes de sucesso. Interciencia, 2014, v.39, n. 11, p.780-787.

ONU. População mundial atingiu $\mathbf{7 , 6}$ bilhões de habitantes. 2017. Disponível em https://news.un.org/pt/story/2017/06/1589091-populacao-mundial-atingiu-76-bilhoesdehabitantes. Acesso em 29 Jul. 2019.

PAIVA, B. K. V.; SANTOS, G. O. Embalagens vazias de agrotóxicos no Ceará: um estudo preliminar sobre a problemática social, ambiental e da saúde do trabalhador. ConexõesCiências e Tecnologia. v.12, n. 1, p. 61 - 71, mar. 2018. Disponível em: < http://conexoes.ifce.edu.br/index.php/conexoes/article/view/1239/1178> Acesso em 25 Abr. 2019.

SILVA, M. G. P. Diagnóstico da situação do sistema plantio direto em Salvador das Missões - RS. 2018. 54 f. Trabalho de Conclusão de Curso (Bacharel em agronomia). Universidade Federal da Fronteira Sul, Cerro Largo. Disponível em: < https://rd.uffs.edu.br/bitstream/prefix/2378/1/SILVA.pdf> Acesso em 18 Jul. 2019.

SILVEIRA, V. C.; PRATES, N. DE O.; EDUARDO, A. S.; RIBEIRO, J. S.; CHAEBO, G. Estudo da produção científica da temática de impactos ambientais relacionados ao agronegócio brasileiro. IN: II Encontro Internacional de Gestão, Desenvolvimento e Inovação. 2018. Naviraí - MS. Disponível em: < http://www.seer.ufms.br/index.php/EIGEDIN/article/view/7033/pdf_25> Acesso em 20 Mar. 2019.

SOUSA, F. R.; OLIVEIRA, N. A. DE M. Externalidades negativas causadas ao meio ambiente pela expansão do agronegócio no Brasil sob a óptica do direito. 2018. Disponível em:

<https://bibliotecadigital.trt18.jus.br/bitstream/handle/bdtrt18/7915/Norma\%20Oliveira\%20e xternalidades.pdf?sequence=1\&isAllowed=y> Acesso em 20 Mar. 2019.

SOUZA, J. A. B.; SOUZA JÚNIOR, I. P.; VIEIRA, S. C. Logística Reversa das Embalagens Vazias de Agrotóxicos: Conscientizar para Fomentar um Agronegócio Sustentável. Fórum Ambiental, v. 13, n. 2, 2017.

STEFFEN NETO, F. Participação do Estado e desempenho de projetos complexos de infraestrutura no agronegócio brasileiro. 2015. 92 f. Dissertação (Mestrado Profissional em Administração). Universidade Nove de Julho, São Paulo. Disponível em: < 
http://repositorio.uninove.br/xmlui/bitstream/handle/123456789/1193/Frederico\%20Steffen\% 20Neto.pdf?sequence=1> Acesso em 18 Jul. 2019.

VALLE NETO, M. C. A sustentabilidade como diferencial competitivo no agronegócio brasileiro. 2014. 38 f. Trabalho de Conclusão de Curso (Especialista em Agronegócio). Universidade Federal do Paraná, Curitiba. Disponível em: < https://www.acervodigital.ufpr.br/bitstream/handle/1884/49859/R\%20-\%20E\%20-

\%20MOZART\%20CESAR\%20VALLE\%20NETO.pdf?sequence=1 > Acesso em $18 \mathrm{Jul}$. 2019.

VELHO, J. P. L.; MACHADO, C. R. Educação Ambiental, Sustentabilidade e Justiça Ambiental: Reflexões sobre a injustiça do Agronegócio no Extremo sul do Brasil. Revista Eletrônica do Mestrado Educação Ambiental, v. 35, n. 3, p. 23-45, set./dez. 2018. Disponível em: < https://periodicos.furg.br/remea/article/view/7875/5549> Acesso em 20 Abr. 2019. 